\title{
$\angle$ Research Square \\ Eleutheroside-b and e in Acanthopanax Senticosus has Anti-PRV Activity via an Enhanced Body Immune Response in Vivo
}

\section{Zuohua Li}

Hunan Agricultural University College of Animal Science and Technology

\section{Xinglong Yu}

Hunan Agricultural University College of Animal Science and Technology

Bin Zhang ( $\nabla$ zhb8236@126.com )

Hunan Agricultural University, Changsha

\section{Research}

Keywords: Acanthopanax senticosus extract, PRV, IFN-y, IL-2, IL-10

Posted Date: October 7th, 2020

DOI: https://doi.org/10.21203/rs.3.rs-85983/v1

License: (c) (1) This work is licensed under a Creative Commons Attribution 4.0 International License.

Read Full License 


\section{Abstract}

\section{Background}

Acanthopanax senticosus extract (Eleutheroside-b and e, Acanthopanax senticosus extract, AS) is a multi-functional medicine involving in antiviral response in rodents and humans. Pseudorabies virus (PRV) is essential pathogens especially in swine farms. However, little is known about the biological functions of AS in vivo during PRV infection.

\section{Methods}

In order to confirm function of AS during PRV infection in vivo. We investigated that AS treatment $(2 \mathrm{mg} / \mathrm{g}$, $4 \mathrm{mg} / \mathrm{g}$ and $6 \mathrm{mg} / \mathrm{g}$ ) mice for 5 days affecting the mouse survival time during PRV infection. Furthermore, we investigated that AS treatment $(4 \mathrm{mg} / \mathrm{g})$ mice for 1 day, 3 days and 5 days, respectively, affected the mouse survival time during PRV infection. We then treated mice with AS $(4 \mathrm{mg} / \mathrm{g})$ for 5 days and then challenged with PRV. Three days after PRV infection, we harvested mouse-samples to analyze PRV copies, performed pathological and immunohistochemical assays and the expression of immune-genes.

Results

We found that AS treatment decreased the PRV copies and degree of pathological damage in mice brains and lungs. The AS treatment also stimulated a high level of IFN-ץ, IL-2, and CCL-5 in the rodent serum, but suppressed IL-10 expression, suggesting that AS enhances the immunity response.

\section{Conclusions}

we showed that AS promoted the anti-PRV ability in vivo by activating the expression of immunity genes. In summary, these findings offer a novel understanding of the immunity response during PRV infection.

\section{Background}

Acanthopanax senticosus extract (AS; also called Siberian Ginseng, Eleutherococcus senticosus, and Ciwujia in China) is a traditional Chinese medicine in the Chinese pharmacopeia. It is widely prescribed to nourish qi, fortify the spleen, tonify the kidney, and tranquilize the mind (Shiokawa et al., 2019). AS is popularly used as an "adaptogen" like Panax ginseng. An increasing number of chemical, pharmacological, and clinical studies on AS have been carried out worldwide. Several kinds of chemical compounds have been reportedincluding triterpenoidsaponins, lignans, coumarins, and flavones.

In the 1980s, AS was shown to enhance the immune-modulatory effect clinically. Scientists demonstrated that an ethanolic AS preparation caused a drastic increase in the absolute number of immunecompromised cells with a noticeable effect on T lymphocytes (predominantly helper cells) as well as cytotoxic and natural killer cells in healthy volunteers (Miyazaki et al., 2018; Zhou et al., 2018a; Zhou et al., 2018b). 
Pseudorabies virus (PRV) is the causative pathogen in Aujeszky's disease and has caused huge economic losses in the pork industry. PRV belongs to the Alphaherpesvirinae subfamily and can infect pigs, mice, even humans (An et al., 2013). It is a double-stranded linear DNA virus with a $150 \mathrm{~kb}$ genome that encodes approximately 100 proteins. The PRV viral envelope contains 11 glycosylation-modified membrane proteins including the essential glycoproteins $\mathrm{gB}, \mathrm{gD}, \mathrm{gH}$, and $\mathrm{gL}$ as well as non-essential glycoproteins gC, gE, gl, gG, gM, gN, and Gk (Setas Pontes et al., 2015; Tong et al., 2016). All strains and ages of pigs are susceptible to PRV including a variety of domestic and wild animals. PRV has neurotropism and transsynaptic transmission (Ye et al., 2015) since 2011 due to the emergence of a mutant pseudorabies viral strain. The disease continues to cause substantial economic losses to animal husbandry especially the pork industry (Liu et al., 2020).

While chemical antiviral drugs can kill viruses, they also often damage to host cells with disadvantages in terms of drug resistance and drug residues. Chinese herbal medicine can have antiviral activity and has attracted increasing attention from researchers (Guo et al., 2020; Li et al., 2020b). AS is an Araliaceae plant, and its main active ingredients are total glycosides and polysaccharidesas well as opizidine, flavonoids, and organic acids (Shiokawa et al., 2019). AS has been extensively studied and applied in human medicine, and studies in rats (Lee et al., 2019; Meng et al., 2017) have also shown that AS enhances immune function with antioxidant, antibacterial, anti-virus, and anti-fatigue functions (Zhang et al., 2019). However, whether AS can resist PRV infection and whether it can be used clinically to treat or prevent PRV infection remains unknown.

Here, we investigated the function of AS in the role of anti-PRV infection in mice. We demonstrate for the first time that AS treatment enhances body immunity and reduces pathological damage to the brain and lungs during PRV infection.

\section{Materials And Methods}

\section{Ethics Statement}

All animal experiments were performed in compliance with the Guidelines on the Humane Treatment of Laboratory Animals (Ministry of Science and Technology of the People's Republic of China, Policy No. 2006 398). This work was also conducted in accordance with the Chinese guidelines for animal welfare while the experimental protocol was approved by the Animal Care and Use Committee of The Chinese Academy of Sciences (Ethics Approval Code: IAS2019-32)

\section{Reagents}

Eleutheroside-b and e, Acanthopanax senticosus extract. The mouse IL-2, IL-4, IL-10, IFN- $\gamma$, CCL-5 ELISA kits were all purchased from Wuhan Merck Biotechnology Co., Ltd. (Wuhan Merck Biotechnology, Wuhan, China); Nucleic Acid Extraction Kit (Axygen, CA, USA), Porcine Pseudorabies Virus Single Fluorescence PCR Detection Kit (Esenbao, Beijing, China), Real-time Fluorescence Quantitative PCR Reaction Reagent Purchased from Takara Biotechnology (Takara Biotechnology, Dalian, China). 


\section{Preparation of mouse diet}

Mixed the extract of Acanthopanax senticosus with the common mouse feed by a small medicinal material pulverizer. The addition amount of the extract of Acanthopanax senticosus was $2 \mathrm{mg} / \mathrm{g}, 4 \mathrm{mg} / \mathrm{g}$, $6 \mathrm{mg} / \mathrm{g}$ or free. Add an appropriate amount of double-distilled water, stir and mix well, shape with a mold, drying it at a condition of $60^{\circ} \mathrm{C}$, after 24 hours storing for use.

\section{Animals and infection}

SPF ICR mouse of 7-week-old was purchased from Hunan Slack Jingda Experimental Animal Co., Ltd. All of the animal experiments were performed following the rules approved by the Animal Care and Use Committee. The Bartha-K61 vaccine strain was maintained at the animal Food Safety Key Laboratory (Hunan Province, China). A total of 50-70 SPF ICR mice from 7-week-old were divided into 4-5 groups (710 mice per group). The infection method was subcutaneous injection into the foot pad. After infection, each group continued to feed according to the pre-infection dosing plan. Observe the death time and number of mice.10-Mice per group were inoculated with 50 $\mu \mathrm{L}$ of DMEM and constituted the control group (Ye et al., 2018). The infection amount was $1.0 \times 10^{5} \mathrm{TCID} 50$, and the dose was $50 \mu \mathrm{L} / \mathrm{mouse}$. All animal experiments were performed in accordance with the Guidelines for the Care and Use of Laboratory Animals of the institution and under the protocols approved by the Institutional Animal Care and Use Committee.

\section{Determination of the optimal feeding concentration of Eleutheroside-b and $e$}

50 female ICR mice were randomly divided into 5 experimental groups, 10 mouse/group. Mice were fed with AS (eleutheroside-b and e) of $2 \mathrm{mg} / \mathrm{g}, 4 \mathrm{mg} / \mathrm{g}, 6 \mathrm{mg} / \mathrm{g}$ or free AS, respectively. The control group was infected and feed without medicine. Each group started to be infected after 5 days of feeding (Fig. 1). The infection amount was $1.0 \times 10^{5} \mathrm{TCID} 50$, and the dose was $50 \mu \mathrm{L} /$ mouse. The infection method was subcutaneous injection into the foot pad. After infection, each group continued to feed according to the pre-infection dosing plan, and observe the death time and number of mice.

\section{Determination of the best feeding time of AS}

50 female ICR mice were randomly divided into 5 experimental groups, 10 mouse/group. Mouse were fed with AS (eleutheroside-b and e) of $4 \mathrm{mg} / \mathrm{g}$ or free AS for 1 day, 3 days and 5 days (Fig. 1). The control group was infected and feed without medicine. The infection amount was $1.0 \times 10^{5}$ TCID50, and the dose was $50 \mu \mathrm{L} /$ mouse. The infection method was subcutaneous injection into the foot pad. After infection, each group continued to feed according to the pre-infection dosing plan, and observe the death time and number of mice.

\section{RNA isolation and qRT-PCR}

Total RNA was extracted by the TRIzol method (Invitrogen, Carlsbad, CA, USA). cDNA was prepared using PrimeScript ${ }^{\text {TM }}$ RT Reagent kit. Then qRT-PCR was performed using a SYBR Premix Ex Taq kit (TaKaRa, 
Japan). Specific primers were shown in Table S1. GAPDH expression was used as a reference. The relative expression was calculated as $2^{-\triangle \Delta C T}$ method (Neal et al., 2017).

\section{Pathological and Immunohistochemical Assays}

Mice feeding with eleutheroside-b and e (extract of Acanthopanax senticosus, Xiaocao Biotechnology, Xi'an, China) or NC, then infected PRV. Tissue samples were collected from the mice and subjected to histopathological and immunehistochemical assays. For histopathological assays, the tissue sections were stained with hematoxylin and eosin. For immunehistochemical assays, the tissue sections were probed with antibodies specific to PRV gE protein.

\section{Detection of PRV copies by q-PCR}

Copies of the PRV UL54 in samples collected from mice were quantified by qRT-PCR with the primers 5'TGCAGCTACACCCTCGTCC -3' and 5'- TCAAAACAGGTGGTTGCAGTAAA -3'. Briefly, Viral DNA was extracted from the samples using QIAGEN viral DNA Kit (QIAamp DNA Mini Kit). The recombinant plasmid PMD19T-UL54 diluted by 10 -fold ratio was used as a quantitative detection template, and realtime fluorescent quantitative PCR (Quantitative Real-time PCR, q-PCR) was performed to obtain the amplification curve and the standard curve. Calculate the copy number of the sample according to the standard curve.

\section{Statistical analyses}

All data were performed with SPSS 18.0 (IBM, NY, USA) using a one-way ANOVA, or analyzed using the software GraphPad Prism version 5.01 (GraphPad Software, Inc., La Jolla, CA, USA). Statistical significance was assessed using an unpaired student's t-test. A value of $p<0.05$ was considered to indicate statistical significance. Data are given as the mean \pm standard deviation (SD).

\section{Results}

\section{Determination of the optimal feeding concentration and optimal feeding time of AS extract}

To study the impact of AS function on PRV infection in vivo, we performed an experiment in which mice were treated with $2 \mathrm{mg} / \mathrm{g}, 4 \mathrm{mg} / \mathrm{g}, 6 \mathrm{mg} / \mathrm{g}$, or a negative control for 5 days. We then infected them with PRV or used a mock infected group for five groups. After five days of PRV infection, we observed that 4 $\mathrm{mg} / \mathrm{g}$ and $6 \mathrm{mg} / \mathrm{g}$ treatment groups had delayed progression versus the PRV-NC and $2 \mathrm{mg} / \mathrm{g}$ AS-group (Fig. 1a). We then selected different treatment times for $4 \mathrm{mg} / \mathrm{g}$-AS feeding mouse to study AS interaction with PRV-infection. The survival data show that AS-3-day and AS-5-day can delay mouse progression of death and pathogenesis versus PRV-NC and AS-1-day group (Fig. 1b). We determined AS-4 mg/g treatment for 5 days was optimal and used for the next assay.

\section{AS affects viral loads of PRV in mouse}


Mice treated with AS- $4 \mathrm{mg} / \mathrm{g}$ for 5 days were then infected with PRV and compared to the PRV-NC group. After infection for 3 days, we harvested the organs to investigate PRV UL54 gene expression in different tissues by q-PCR. The AS group had a lower level of virus in the brain, lung, spleen, and inguinal lymph node tissues compared to the PRV NC group (Fig. 2).

\section{AS treatment can reduce histopathological damage in PRV-infected mice}

AS significantly reduces PRV copies in mice brain and lung; thus, we performed HE staining assay for analysis of histopathological damage. PRV in the control group (PRV NC) brains showed typical nonsuppurative meningitis pathological changes. There was cerebral edema, glial cell nodules, and vascular sheaths formed by monocytes; AS treatment significantly reduced brain damage (Fig. 3). PRV NC-lungs showed typical interstitial pathological changes of pneumonia including edema, hyperemia, bleeding, thickened alveolar wall, and inflammatory cell infiltration, but AS treatment can reduce these pathological phenomena (Fig. 3). The $4 \mathrm{mg} / \mathrm{g}$ of AS extract can alleviate the pathological changes in the brain and lung of mice with PRV.

IHC staining showed that the brain and lungs of the mice in the mock group were negative. PRV NC-brain and lung data showed positive antigens with the strongest antigen signal in the lungs and weaker brains. This suggests that the lung contain more virus than the brain (Fig. 3). PRV AS-brain and lung viral antigen were also positive, but AS treatment mice brain and lung showed a low level of positive viral antigens (Fig. 3). These results are consistent with the HE results suggesting that the AS extract can reduce the PRV loads in the mouse tissues, brain and lung.

\section{AS promoting immune-related cytokine secretion in mouse serum}

Four cytokines (IL-2, IL-10, IFN-y and CCL-5) were detected with ELISA. AS treatment increased the secretion of IL2, IFN- - , and CCL-5 compared to PRV NC group; these are cytokines involved in an anti-viral response (Fig. 4); and PRV infection was unable to induce these cytokines-production in mouse serum. IL10 has a central anti-inflammatory role in mammals and potently suppresses IFN-y responses. IL-10 can suppress a range of aberrant immune responses, and AS treatment decreased IL-10 secretion versus the PRV NC group (Fig. 4).

\section{Discussion}

Numerous Chinese herbal medicines have been widely used for the prevention and cure of viral diseases in China and other Asian countries for thousands of years(Lau et al., 2019). Examples include Formula Le-Cao-Shi (LCS), a traditional Chinese medicine (TCM) that exerts antiviral effects against Hepatitis B Virus; Radix isatidis polysaccharide inhibits PRV replication (Tong et al., 2020). AS is a TCM that can inhibit and destroy pathogenic microorganisms, AS promotes animal health. However, the impact on PRV was unknown before this study. This is important to know because PRV causes enormous economic losses in agriculture with a few cases even in humans (Fan et al., 2020; Li et al., 2020a). PRV has a broad host range, and mice are a good model to study PRV including their immune response. In this study, we 
focused on AS feeding and how it affects PRV infection in mice. We first studied the optimal feeding dose and time. Feeding mouse with AS increased the survival rate as a function of dose. AS at $4 \mathrm{mg} / \mathrm{g}$ for five days was optimal and used for subsequent experiments.

Additionally, our previous cell experiments showed that the appropriate dose of AS can significantly inhibit the proliferation of PRV in PK-15 cells (data not shown). These studies motivated us to determine whether an extract of AS had an inhibitory effect on PRV infection in vivo. We also performed preliminary research on the mechanism of anti-PRV infection.

Our data showed that feeding AS can significantly inhibit PRV proliferation in the brain, lung, and inguinal lymph nodes. Continuous feeding for 5 days can substantially reduce damage to target tissues by PRV. We also observed the antigens of PRV in AS group lung and brain were significantly lower than those in the control group.

PRV could not induce expression of immune-active genes in mice. Radix isatidis can inhibit the replication of human influenza viruses (H1N1 and H3N2) and avian influenza viruses (Li et al., 2017) via its antiviral activities (Du et al., 2013). In this study, AS was shown to inhibit PRV infection, enhance expression of immune-related genes, and activate inflammatory cytokine production.

We also found that AS extract can promote the production of CCL-5, IFN- $\gamma$, and IL-2 during PRV infection. It inhibits IL-10 production in mouse serum suggesting that AS can significantly strengthen the immune response and fight PRV infection. Inflammatory factors such as IFN- $\gamma$ can arrange numerous protective functions to improve immune responses during infections. These show immunomodulatory effects by enhancing antigen processing to increase leukocyte trafficking and induce an anti-viral state (Kak et al., 2018). IL-2can promote the proliferation of T-cells and generate effector and memory cells (Cho et al., 2013); AS feeding mice have high levels of IL-2 in serum. The upregulation of IL-2, IFN-Y, and CCL-5is related to anti-PRV infection.

\section{Conclusions}

Traditional Chinese medicines have many targets with minor side effects, they have bright application prospects. Here, for first time, we obtained evidence for the anti-PRV activity of Acanthopanax senticosus extract in vivo. We showed that Acanthopanax senticosus extract promoted the anti-PRV ability in vivo by activating the expression of immunity-genes. In summary, these findings offer a novel understanding of the immunity response during PRV infection.

\section{Abbreviations}

PRV: Pseudorabies virus; AS: Acanthopanax senticosus extract.

\section{Declarations}


Acknowledgements

We are thankful to Ms. Lina Wang for helping in the discussion of the experiments.

\section{Authors' contributions}

L. Z. and B. Z. wrote the manuscript. L. Z., and Y. X. design and performed the experiments. L. Z. and B. Z. analyzed the data and contributed to manuscript writing. All of authors read and approved the final manuscript.

\section{Funding}

This work is no funding to support.

\section{Availability of data and materials}

The datasets used and/or analyzed during the current study are available from the corresponding author on reasonable request.

\section{Ethics declarations}

\section{Ethics approval and consent to participate}

Mouse experiment was according to the Humane Treatment of Laboratory Animals (Ministry of Science and Technology of the People's Republic of China, Policy No. 2006 398). This work was also conducted in accordance with the Chinese guidelines for animal welfare while the experimental protocol was approved by the Animal Care and Use Committee of The Chinese Academy of Sciences (Ethics Approval Code: IAS2019-32).

\section{Consent for publication}

All authors have read and agreed to publish the paper.

\section{Competing interests}

The authors declare that they have no conflict.

\section{Author details}

1 College of Aniaml Science and Technology, Hunan Agricultural University, Changsha, Hunan 410128; 2 College of Veterinary Medicine, Hunan Agricultural University, Changsha, Hunan 410128.

\section{References}

An, T.Q., Peng, J.M., Tian, Z.J., Zhao, H.Y., Li, N., Liu, Y.M., Chen, J.Z., Leng, C.L., Sun, Y., Chang, D., Tong, G.Z., 2013. Pseudorabies virus variant in Bartha-K61-vaccinated pigs, China, 2012. Emerging infectious 
Cho, J.H., Kim, H.O., Kim, K.S., Yang, D.H., Surh, C.D., Sprent, J., 2013. Unique features of naive CD8+ T cell activation by IL-2. Journal of immunology 191, 5559-5573.

Du, Z., Liu, H., Zhang, Z., Li, P., 2013. Antioxidant and anti-inflammatory activities of Radix Isatidis polysaccharide in murine alveolar macrophages. International journal of biological macromolecules 58 , 329-335.

Fan, S., Yuan, H., Liu, L., Li, H., Wang, S., Zhao, W., Wu, Y., Wang, P., Hu, Y., Han, J., Lyu, Y., Zhang, W., Chen, P., Wu, H., Gong, Y., Ma, Z., Li, Y., Yu, J., Qiao, X., Li, G., Zhao, Y., Wang, D., Ren, H., Peng, B., Cui, L., Wang, J., Guan, H., 2020. Pseudorabies virus encephalitis in humans: a case series study.

Guo, L., Qi, J., Du, D., Liu, Y., Jiang, X., 2020. Current advances of Dendrobium officinale polysaccharides in dermatology: a literature review. Pharmaceutical biology 58, 664-673.

Kak, G., Raza, M., Tiwari, B.K., 2018. Interferon-gamma (IFN-y): Exploring its implications in infectious diseases. Biomolecular concepts 9, 64-79.

Lau, K.M., Yue, G.G., Chan, Y.Y., Kwok, H.F., Gao, S., Wong, C.W., Lau, C.B., 2019. A review on the immunomodulatory activity of Acanthopanax senticosus and its active components. 14, 25.

Lee, D., Lee, S.H., Cho, N., Kim, Y.S., Song, J., 2019. Effects of Eleutherococcus Extract Mixture on Endochondral Bone Formation in Rats. 20.

Li, X.D., Fu, S.H., Chen, L.Y., Li, F., Deng, J.H., Lu, X.C., Wang, H.Y., Tian, K.G., 2020a. Detection of Pseudorabies Virus Antibodies in Human Encephalitis Cases. Biomedical and environmental sciences : BES 33, 444-447.

Li, Y., Gao, Y., Gong, Y., Guo, Y., Wang, L., Liu, Q., Chen, F., Zhang, T., 2020b. Treatment with Tang-luo-ning altered the microRNA expression profile in rats with diabetic peripheral neuropathy. 11, 841-851.

Li, Z., Li, L., Zhou, H., Zeng, L., Chen, T., Chen, Q., Zhou, B., Wang, Y., Chen, Q., Hu, P., Yang, Z., 2017. Radix isatidis Polysaccharides Inhibit Influenza a Virus and Influenza A Virus-Induced Inflammation via Suppression of Host TLR3 Signaling In Vitro. Molecules (Basel, Switzerland) 22.

Liu, Q., Wang, X., Xie, C., Ding, S., Yang, H., Guo, S., Li, J., Qin, L., Ban, F., Wang, D., Wang, C., Feng, L., Ma, H., Wu, B., Zhang, L., Dong, C., Xing, L., Zhang, J., Chen, H., Yan, R., Wang, X., Li, W., 2020. A novel human acute encephalitis caused by pseudorabies virus variant strain. Clinical infectious diseases : an official publication of the Infectious Diseases Society of America.

Meng, F., Li, Y., He, G., Ge, G., Liu, S., 2017. Identification of human UDP-glucuronosyltransferase isoforms involved in the isofraxidin glucuronidation and assessment of the species differences of the reaction.

Fitoterapia 117, 118-125. 
Miyazaki, S., Oikawa, H., Takekoshi, H., Hoshizaki, M., Ogata, M., Fujikawa, T., 2018. Anxiolytic Effects of Acanthopanax senticosus HARMS Occur via Regulation of Autonomic Function and Activate Hippocampal BDNF囚TrkB Signaling. Molecules (Basel, Switzerland) 24.

Neal, L.M., Qiu, Y., Chung, J., Xing, E., Cho, W., Malachowski, A.N., Sandy-Sloat, A.R., Osterholzer, J.J., Maillard, I., Olszewski, M.A., 2017. T Cell-Restricted Notch Signaling Contributes to Pulmonary Th1 and Th2 Immunity during Cryptococcus neoformans Infection. J Immunol 199, 643-655.

Setas Pontes, M., Devriendt, B., Favoreel, H.W., 2015. Pseudorabies virus triggers glycoprotein gEmediated ERK1/2 activation and ERK1/2-dependent migratory behavior in T cells. Journal of virology 89, 2149-2156.

Shiokawa, Y., Miyauchi-Wakuda, S., Kagota, S., Maruyama-Fumoto, K., Yamada, S., Shinozuka, K., 2019. Acanthopanax senticosus Induces Vasorelaxation via Endothelial Nitric Oxide-Dependent and Independent Pathways. Planta medica 85, 1080-1087.

Tong, C., Chen, Z., Liu, F., Qiao, Y., Chen, T., Wang, X., 2020. Antiviral activities of Radix isatidis polysaccharide against pseudorabies virus in swine testicle cells. BMC complementary medicine and therapies 20, 48.

Tong, W., Li, G., Liang, C., Liu, F., Tian, Q., Cao, Y., Li, L., Zheng, X., Zheng, H., Tong, G., 2016. A live, attenuated pseudorabies virus strain JS-2012 deleted for $\mathrm{gE} / \mathrm{gl}$ protects against both classical and emerging strains. Antiviral research 130, 110-117.

Ye, C., Chen, J., Wang, T., Xu, J., Zheng, H., Wu, J., Li, G., Yu, Z., Tong, W., Cheng, X., Zhou, S., Tong, G., 2018. Generation and characterization of UL41 null pseudorabies virus variant in vitro and in vivo. Virology journal 15, 119.

Ye, C., Zhang, Q.Z., Tian, Z.J., Zheng, H., Zhao, K., Liu, F., Guo, J.C., Tong, W., Jiang, C.G., Wang, S.J., Shi, M., Chang, X.B., Jiang, Y.F., Peng, J.M., Zhou, Y.J., Tang, Y.D., Sun, M.X., Cai, X.H., An, T.Q., Tong, G.Z., 2015. Genomic characterization of emergent pseudorabies virus in China reveals marked sequence divergence: Evidence for the existence of two major genotypes. Virology 483, 32-43.

Zhang, N., Zhao, L.Y., Mao, D., Du, Z.Y., Zhang, X.J., Zhai, X.N., An, B.S., Liu, S.M., 2019. [Modulation effect of Acanthopanax senticosus polysaccharides through inflammatory cytokines in protecting immunological liver-injured mice]. Zhongguo Zhong yao za zhi = Zhongguo zhongyao zazhi = China journal of Chinese materia medica 44, 2947-2952.

Zhou, A.Y., Song, B.W., Fu, C.Y., Baranenko, D.D., Wang, E.J., Li, F.Y., Lu, G.W., 2018a. Acanthopanax senticosus reduces brain injury in mice exposed to low linear energy transfer radiation. Biomedicine \& pharmacotherapy = Biomedecine \& pharmacotherapie 99, 781-790. 
Zhou, Y., Cheng, C., Baranenko, D., Wang, J., Li, Y., Lu, W., 2018b. Effects of Acanthopanax senticosus on Brain Injury Induced by Simulated Spatial Radiation in Mouse Model Based on Pharmacokinetics and Comparative Proteomics. International journal of molecular sciences 19.

\section{Figures}

Fig. 1

a
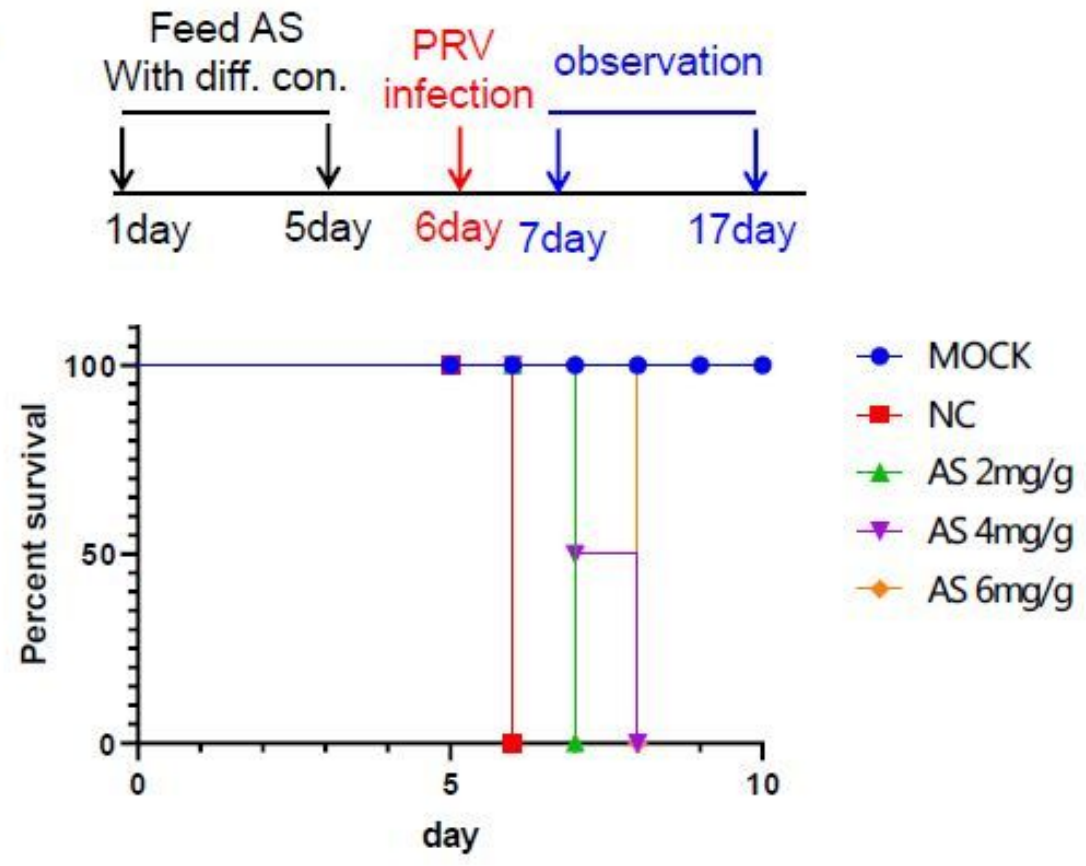

b
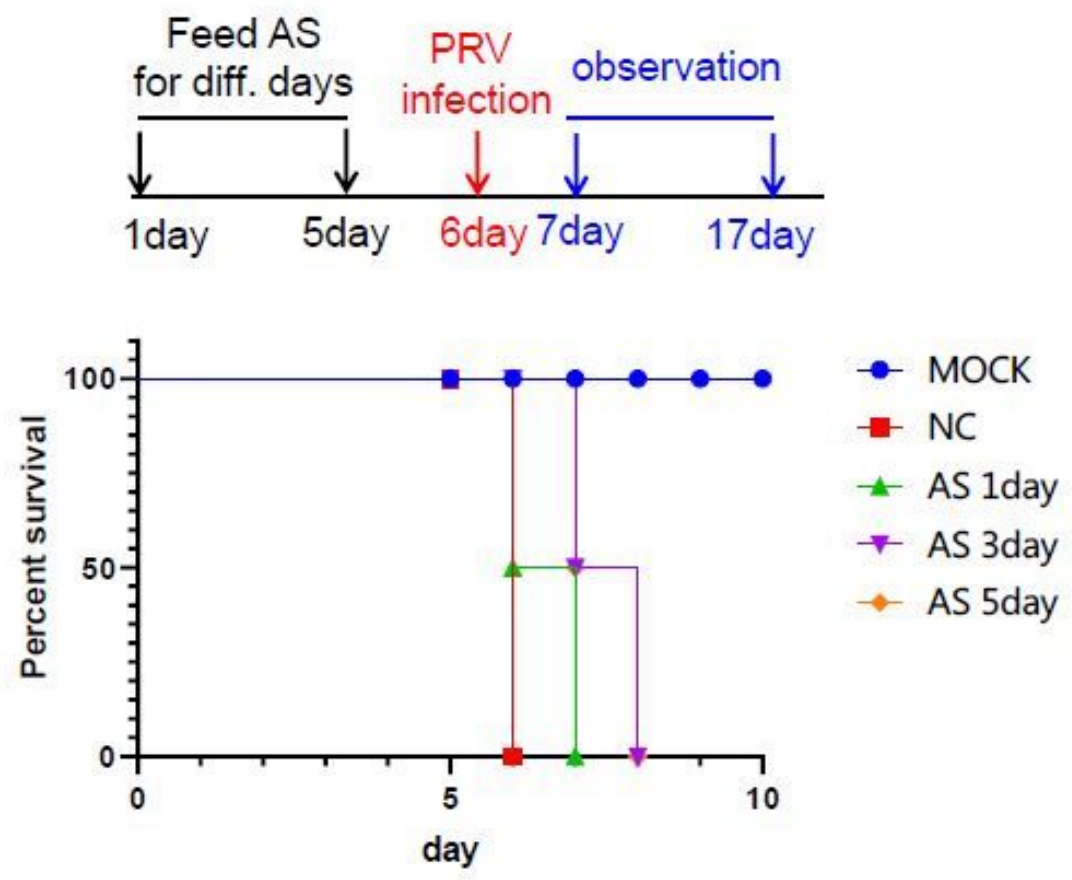
Survival curve. (a) Mice ( $\mathrm{n}=10)$ were fed with Acanthopanax senticosus (AS) $(2 \mathrm{mg} / \mathrm{g}, 4 \mathrm{mg} / \mathrm{g}$ or $6 \mathrm{mg} / \mathrm{g}$ ) or free AS daily 5 days. Mice were exposed to mock- and PRV-infected daily for seven days. The mice were monitored daily for 10 days. (b) Mice $(n=10)$ were feed with AS $(4 \mathrm{mg} / \mathrm{g})$ daily for 1 day, 3 days, or 5 days. Mice were exposed to mock- and PRV-infection daily for seven days. The mice were monitored daily for 10 days.

Fig. 2
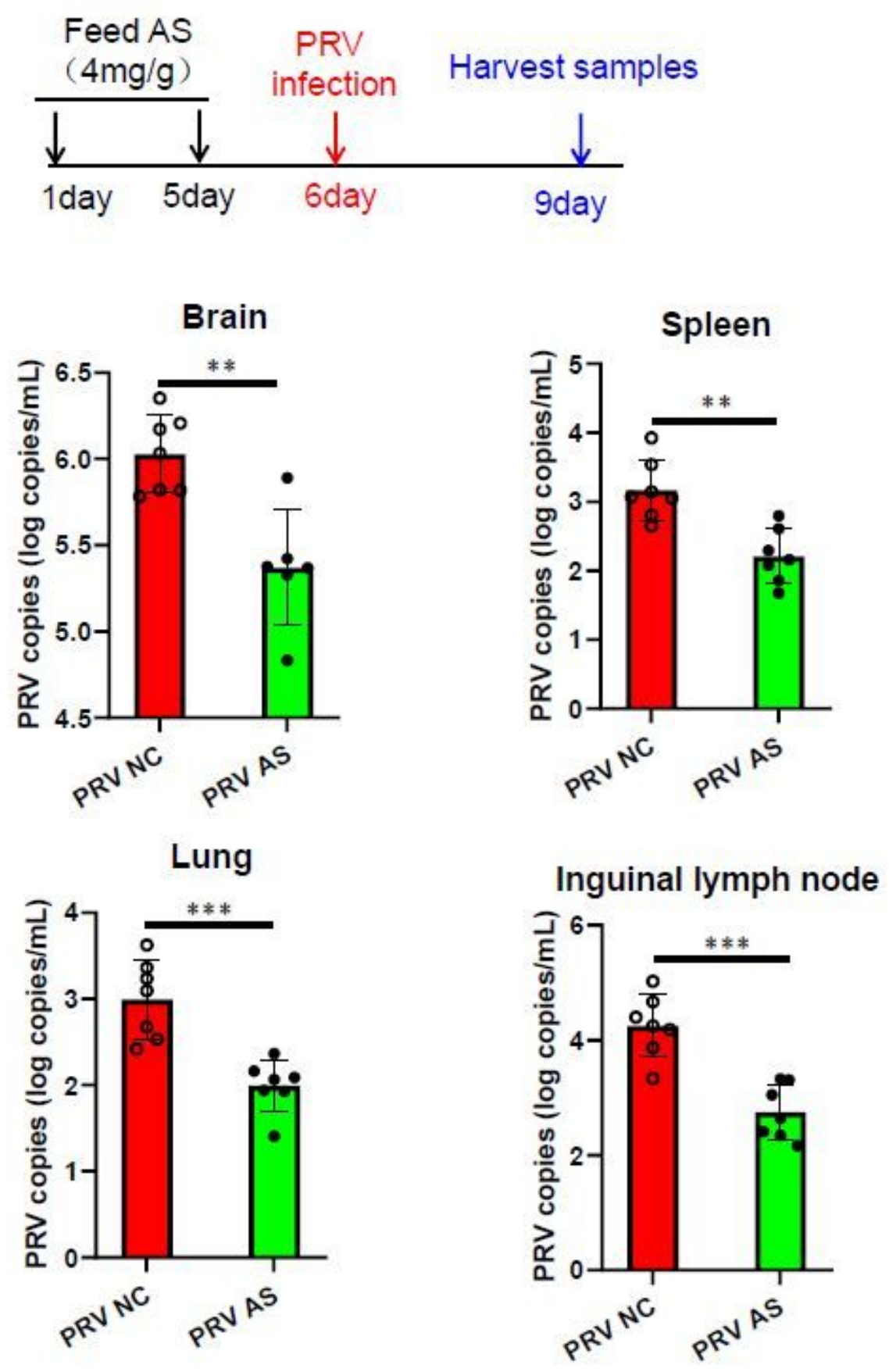

Figure 2 
PRV copies were detected in mice brain, lung, spleen, and inguinal lymph nodes. Mice were fed with 4 $\mathrm{mg} / \mathrm{g}$ Acanthopanax senticosus (AS) or NC for 5 days. They were then infected with PRV, and tissue samples were collected at $3 \mathrm{dpi}(\mathrm{n}=7)$ for analysis of PRV copies by q-PCR. Each dot represents an individual mouse. Data are presented as mean \pm SD from three independent experiments. ${ }^{\star \star} p<0.01 ; * \star * p$ $<0.001$ tested by Student's t-test.

\section{Fig. 3}
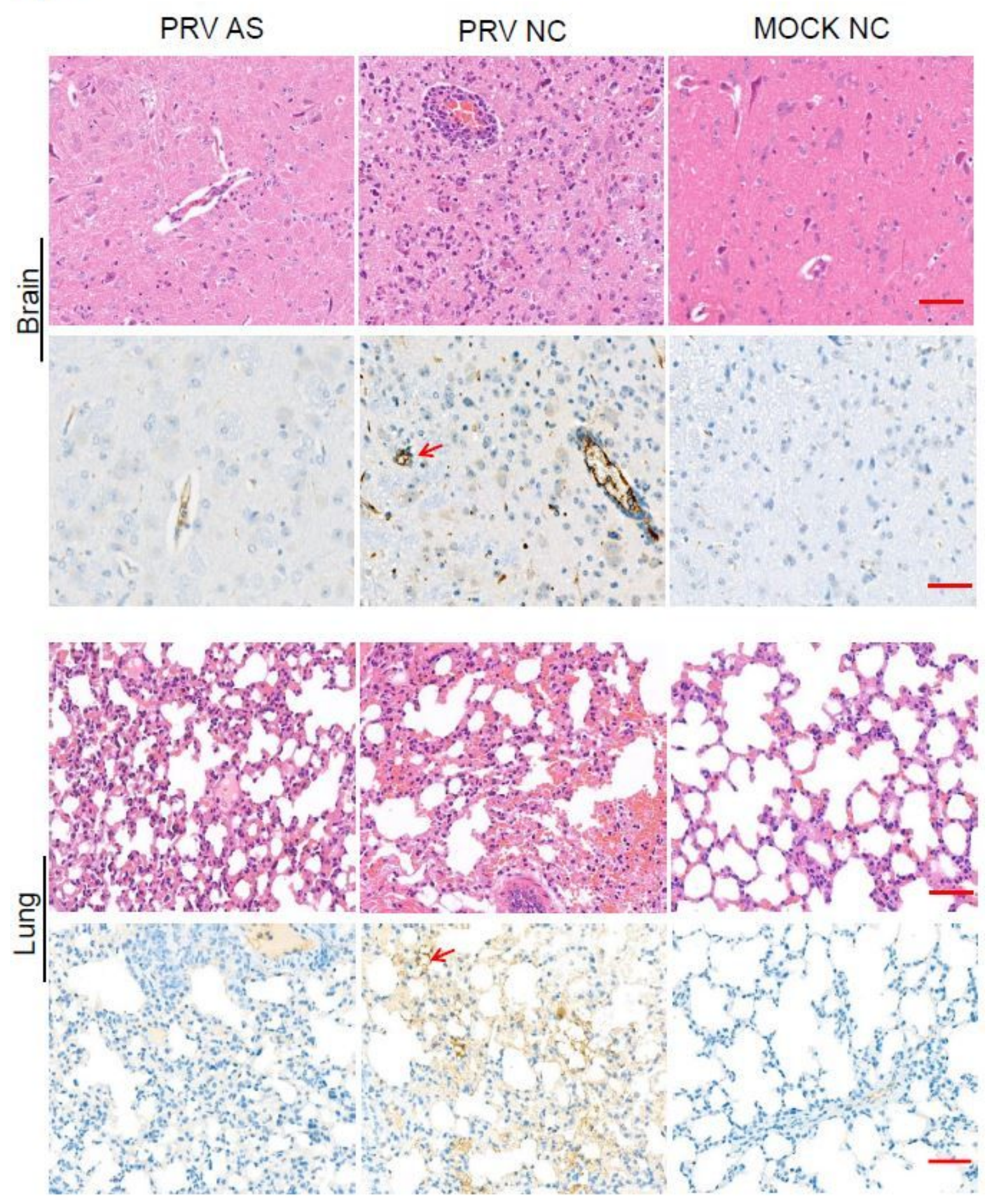

Figure 3 
Pathological lesions. The mice (PRV NC) died at 3 dpi in the group infected with PRV and were examined for pathological lesions as PRV-infected controls. Mice (PRV AS) from the group infected with PRV were euthanized at $3 \mathrm{dpi}$. Brain and lungs were examined by immunohistochemical assays with anti-gB antibodies. The PRV positive cells are indicated by red arrows. Bar: $20 \mu \mathrm{m}$.
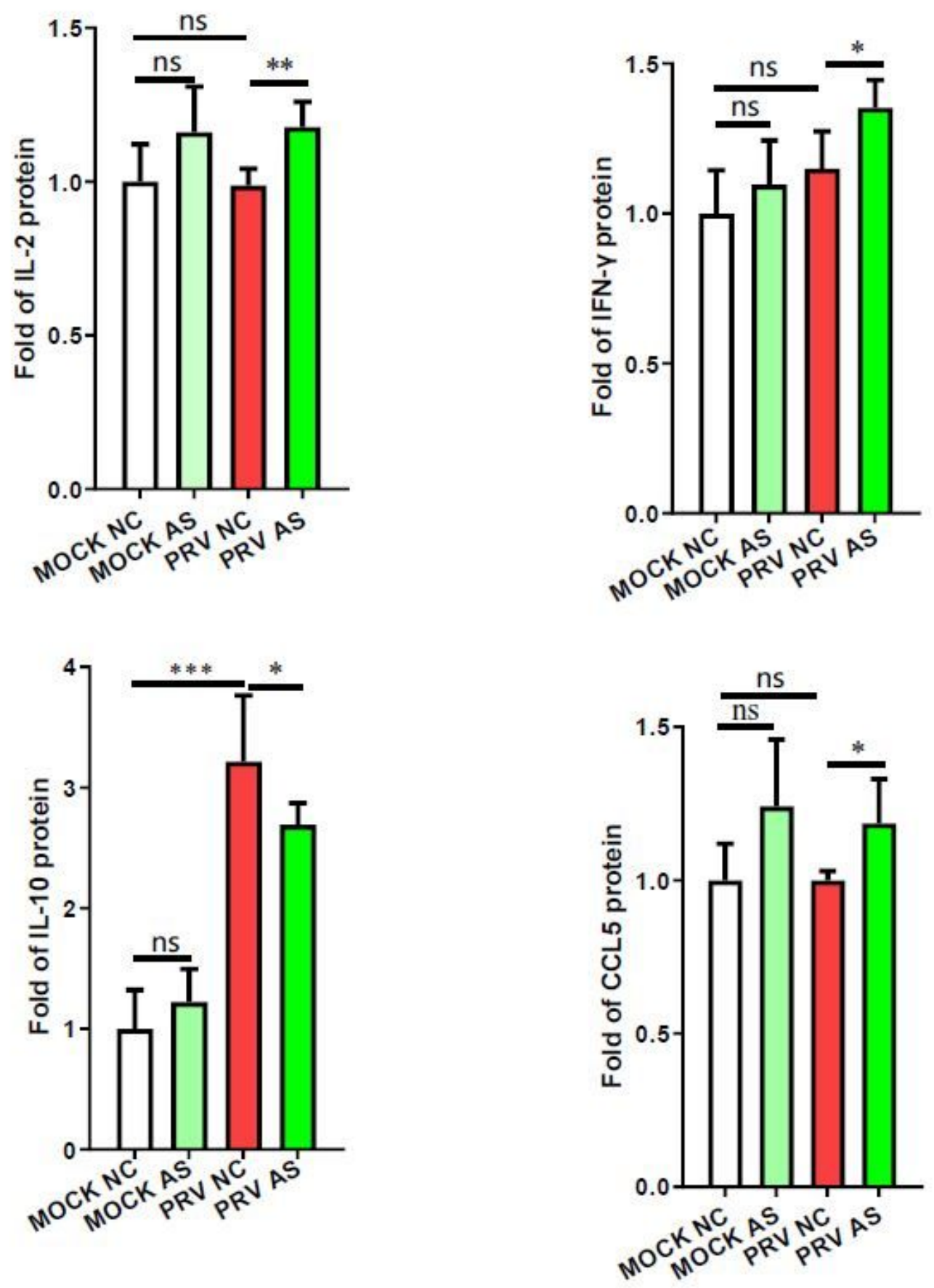

Figure 4 
Production of IL-2, IFN- $y$, CCL-5, and IL-10 was detected in mice serum by ELISA in PRV NC or PRV AS. Data are presented as mean \pm SD from three independent experiments. $N=7$, "ns" is indicated no significant; ${ }^{*}<<0.05 ;{ }^{* \star} p<0.01 ; * \star \star p<0.001$ tested by Student's t-test. 